\section{Plant and leaf}

Phytochrome and Photomorphogenesis: An Introduction to the Photocontrol of Plant Development. By Harry Smith. Pp. xiii +235. (McGraw-Hill: London and New York, 1975.) £7.95.

THE quotation from Stephen Hales and the coloured frontispiece illustrating light- and dark-grown seedlings are a fitting introduction to the contents of this book. In the nine chapters that follow the author has analysed how light from particular spectral regions is perceived, measured by the plant and translated through modifications of biochemical pathways into a recognisable pattern of growth and differentiation. Apart from relevant discussion of the spectral activity and nature of the receptor for phototropic responses, growth effects dependent on the direction of light (phototropism) or time of exposure to light (photoperiodism) are not within the scope of this book.

Before describing the evidence for the existence of specific photoreceptor molecules the author has included a chapter on the physical properties of light in relation to action spectra and photochemical response with methods for experimental manipulation of light sources. This will be particularly help-

\section{BOOKS}

\section{ON PURE} AND APPLIED SCIENCE

\section{Books reviewed or men-} tioned in this journal are available from stock.

Catalogues on application. Please state interests.

\section{SCIENTIFIC LIBRARY}

ANNUAL SUBSCRIPTION from $\mathrm{f} 4.00$

Reduced rates for multiple subscriptions Available in U.K. only

Prospectus free on request

H. K. LEWIS \& Co. Ltd.

LONDON: 136 GOWER STREET, WCIE 6BS

Telephone : 01-387 4282 ful to those who are entering this field of photobiology for the first time.

The important experiments leading to the discovery, isolation and identification of a chromoprotein absorbing at red and far-red wavelengths, and the evidence for another receptor absorbing in the blue region of the spectrum, have been carefully culled from the literature, and are dealt with historically and analytically with great clarity. In one chapter the chemical properties of phytochrome are treated in detail, with present views of the likely phototransformations and conversions of the chromophore-protein complex both in vitro and in vivo.

The quantitative detection within the plant, the likely localisation within membranes, and the evidence linking developmental responses to different forms of phytochrome in vivo is presented in a way that leaves the reader in no doubt of the hard facts as well as the problems and paradoxes.

Major proposals for the mechanism of phytochrome action are discussed on the basis of chemical and biological data. The extensive studies of phytochrome involvement in germination and seedling growth form the subject of two chapters, but here some crispness of presentation is lost amongst the many factual details. The longest chapter is devoted to biochemical changes associated with the phytochrome-mediated photocontrol of development.

The book as a whole is carefully and thoughtfully written and easy to read, its many subtitles providing quick reference from one section to another. As a comprehensive survey of the present state of knowledge in the field, with pointers to areas of future study, this work is valuable for students, teachers and research workers and all who wish to learn about phytochrome in plant growth. An informed interest in photomorphogenesis must surely result for anyone who reads this stimulating book. Daphne J. Osborne

The Shoot Apex and Leaf Growth: $A$ Study in Quantitative Biology. By R. F. Williams. Pp. vii +256 . (Cambridge University Press: London, March 1975.) $£ 6.50 ; \$ 18.95$.

THE organisation of leaf primordia at the shoot apex, which in many cases can be described mathematically, is a fundamental and obvious system for studying the concepts of positional information and development of form in plants. It is always surprising to me that the shoot apex has not been exhaustively studied in this respect, compared with the more widely used animal systems. A treatise on the shoot apex and leaf growth is therefore potentially exciting reading to those interested in the development of form. The bulk of this book, 143 out of 223 pages, is devoted to detailed descriptions, ultimately expressed as threedimensional scale drawings, of the vegetative growth of a dozen plant species encompassing a wide range of different developmental patterns. The development of the inflorescence of wheat is also described, and the detailed comparison of vegetative and floral apices provides some insight into the control of floral induction. These results are supplemented by a further 22 pages detailing the more complicated aspects of the methods used in these studies. After reading these sections which, in the author's words "many will be content to treat as resource material ... to check the claims made elsewhere", the potential of the shoot apex as a system for studying the development of form is fully justified. Unfortunately, very little is concluded from this wealth of information, and the author in fact suggests that further "comparative, quantitative morphology of these objects will certainly yield valuable insights in its own right". Perhaps, however, this is the time to put the microtome back on the shelf, and try to formulate the type of "insight" on which this type of analysis may throw some light.

The major conclusion drawn from these studies is the importance of physical constraint on the growth rate of the apex and component parts. Although, with hindsight, this is perhaps an expected dependence, it is well supported by the developmental data from the different types of apex, and tested quite convincingly in a series of experiments involving tiller formation in wheat. The claim that physical constraint may play a part in the genesis of form is less convincing. Whether the physical constraint at the shoot apex is the cause or the result of the phyllotaxis and leaf shape is a moot point. It is disappointing that no attempt has been made to experimentally check this hypothesis.

Preceding these sections on the apical growth studies the book contains an interesting chapter (18 pages) on the quantitative description of growth, indicating the problems involved in analysing the growth of a complex, multicellular system. This chapter sets the scene for the subsequent relatively sophisticated growth analyses of the leaves and apex. The subject of phyllotaxis, and particularly the parameters used in quantitatively describing the phyllotactic systems, are very usefully discussed in an introductory chapter (30 pages), although I found it necessary to refer to the more detailed original treatments of Richards in one or two places.

This book is a very significant contribution in terms of the elegant descriptions and analyses of growth of the shoot apex and leaves, but where do we go from here?
John Ingle 